\title{
Glucose levels during gestational diabetes pregnancy and the risk of developing postpartum diabetes or prediabetes
}

\author{
Chadakarn Phaloprakarn* (10) and Siriwan Tangjitgamol
}

\begin{abstract}
Background: Blood glucose levels during pregnancy may reflect the severity of insulin secretory defects and/or insulin resistance during gestational diabetes mellitus (GDM) pregnancy. We hypothesized that suboptimal glycemic control in women with GDM could increase the risk of postpartum type 2 diabetes mellitus (T2DM) or prediabetes. Our objective was to evaluate the impact of plasma glucose levels throughout GDM pregnancy on the risk of postpartum T2DM or prediabetes.

Methods: The medical records of 706 women with GDM who underwent a postpartum 75-g, 2-hour oral glucose tolerance test at our institution between January 2011 and December 2018 were reviewed. These women were classified into 2 groups according to glycemic control during pregnancy: $\leq 1$ occasion of either fasting glucose $\geq 95 \mathrm{mg} /$ $\mathrm{dL}$ or 2-hour postprandial glucose $\geq 120 \mathrm{mg} / \mathrm{dL}$ was defined as optimal glycemic control or else was classified as suboptimal glycemic control. Rates of postpartum T2DM and prediabetes were compared between women with optimal ( $n=505)$ and suboptimal $(n=201)$ glycemic control.
\end{abstract}

Results: The rates of postpartum T2DM and prediabetes were significantly higher in the suboptimal glycemic control group than in the optimal glycemic control group: $22.4 \%$ vs. $3.0 \%, P<0.001$ for T2DM and $45.3 \%$ vs. $23.5 \%, P<0.001$ for prediabetes. In a multivariate analysis, suboptimal glucose control during pregnancy was an independent risk factor for developing either postpartum T2DM or prediabetes. The adjusted odds ratios were 8.4 (95\% confidence interval, 3.5-20.3) for T2DM and 3.9 (95\% confidence interval, 2.5-6.1) for prediabetes.

Conclusion: Our findings suggest that blood glucose levels during GDM pregnancy have an impact on the risk of postpartum T2DM and prediabetes.

Keywords: Gestational diabetes mellitus, Glucose level, Glycemic control, Postpartum prediabetes, Postpartum type 2 diabetes mellitus

\section{Background}

Gestational diabetes mellitus (GDM) is a common metabolic disorder in pregnancy that affects $20 \%$ to $25 \%$ of Southeast Asian pregnant women [1]. This metabolic derangement is characterized by insufficient insulin

\footnotetext{
*Correspondence: chadakarn_pt@yahoo.com
}

Department of Obstetrics and Gynecology, Faculty of Medicine Vajira Hospital, Navamindradhiraj University, 681 Samsen Road, Dusit District, Bangkok 10300, Thailand secretion from pancreatic $\beta$-cells to compensate for pregnancy-induced physiologic insulin resistance [2]. The coexistence of insulin secretory defects and insulin resistance can raise maternal blood glucose levels, resulting in adverse pregnancy outcomes [3, 4]. These coexisting disorders are also well recognized as important factors in the pathogenesis of prediabetes and type 2 diabetes mellitus (T2DM) [5, 6]. 
Good control of plasma glucose levels throughout gestation among pregnant women with GDM is generally recommended to minimize adverse pregnancy outcomes. Earlier studies have found increased risks of macrosomia and cesarean delivery among women with suboptimal or uncontrolled blood glucose levels compared to women with optimal glycemic control [7, 8]. Aside from pregnancy outcomes, an increased risk of postpartum glucose intolerance or T2DM in women with GDM who had poor glycemic control during pregnancy has been reported [ 9 , 10]. However, the definition of 'good or optimal' vs. 'poor or suboptimal' glucose levels (using the 2-hour postprandial vs. mean daily glucose level) and the time points for the diagnosis or development of T2DM (weeks vs. years postpartum) are inconsistent among previous studies $[9$, 10].

Given that the levels of blood glucose during pregnancy may reflect the severity of insulin secretory defects and/ or insulin resistance during GDM pregnancy [11], we hypothesized that suboptimal glycemic control in women with GDM would impart an increased risk of postpartum T2DM or prediabetes. The aim of this study was to determine the impact of glucose levels during GDM pregnancy on the risk of developing T2DM or prediabetes at 6 weeks postpartum. The criteria for optimal and suboptimal glycemic control were based on the standard recommendations of the American Diabetes Association (ADA) and the American College of Obstetricians and Gynecologists (ACOG) that the fasting plasma glucose (FPG) in GDM pregnancy should be maintained below $95 \mathrm{mg} / \mathrm{dL}$ and the 1-hour or 2-hour postprandial glucose below $140 \mathrm{mg} / \mathrm{dL}$ or $120 \mathrm{mg} / \mathrm{dL}$, respectively [12, 13].

\section{Methods}

\section{Participants}

This retrospective study was performed at the Faculty of Medicine Vajira Hospital, which is an 800-bed tertiary care and referral hospital located in Bangkok, Thailand. Medical records of women with a diagnosis of GDM who delivered and returned to our institution between January 2011 and December 2018 for a 75-g, 2-hour oral glucose tolerance test (OGTT) at 6 weeks postpartum were reviewed. The inclusion criterion was women who had at least four occasions of blood glucose measurements during pregnancy. Women with a diagnosis of pregestational diabetes and those without available data on fasting and/ or postprandial plasma glucose levels during pregnancy were excluded from the study.

\section{Blood glucose testing and diagnosis}

As a standard practice in our institution, all pregnant women without risk factors for GDM underwent a glucose challenge test (GCT) at 24-28 weeks of gestation.
On the other hand, women with risk factors received a screening test at the initial visit and, if negative, were rescreened at 28-32 weeks of gestation. Individuals with a GCT result of $140 \mathrm{mg} / \mathrm{dL}$ or higher would be scheduled for a diagnostic 100-g OGTT. The diagnosis of GDM was based on the Carpenter and Coustan criteria [14].

The management of women with GDM included dietary and lifestyle modifications as initial treatment. These women were evaluated for their levels of glycemic control throughout gestation by the measurement of fasting and 2-hour postprandial plasma glucose levels every 2-4 weeks. Insulin therapy, as determined and prescribed by an endocrinologist, was generally initiated when the FPG was $\geq 95 \mathrm{mg} / \mathrm{dL}$ and/or 2-hour postprandial glucose was $\geq 120 \mathrm{mg} / \mathrm{dL}$. Factors that were also involved in the decision to initiate insulin treatment were the compliance of pregnant women with insulin injections, gestational age at which abnormally high FPG or 2-hour postprandial glucose was detected, and type (fasting or postprandial glucose), magnitude and number of hyperglycemic episodes.

Optimal or suboptimal control of plasma glucose levels was defined according to the thresholds for fasting and 2-hour postprandial glucose recommended by the ADA and ACOG [12, 13]. Optimal glycemic control was defined as no more than one occasion of either an FPG level of at least $95 \mathrm{mg} / \mathrm{dL}$ or a 2-hour postprandial glucose level of at least $120 \mathrm{mg} / \mathrm{dL}$. Suboptimal glycemic control was defined as two or more occasions of an FPG level of at least $95 \mathrm{mg} / \mathrm{dL}$ and/or a 2-hour postprandial glucose level of at least $120 \mathrm{mg} / \mathrm{dL}$.

After delivery, all women with a diagnosis of GDM were scheduled for a 75-g, 2-hour OGTT at 6 weeks postpartum.

\section{Data collection and study outcome}

The data were extracted from medical charts and the hospital's electronic database. These included age, parity, prepregnancy body mass index (BMI), history of T2DM in any first-degree relatives, GCT and 100-g OGTT values, gestational age at GDM diagnosis, insulin use (type and dose), fasting and 2-hour postprandial glucose levels throughout pregnancy, neonatal birth weight, and levels of postpartum 75-g, 2-hour OGTT, which included an FPG and a plasma glucose at 2 hours after the 75 -g glucose load. Data on individual glucose levels throughout pregnancy were collected from regular blood glucose monitoring during antenatal visits.

The primary study outcome was the development of T2DM or prediabetes at 6 weeks postpartum. The diagnosis of T2DM was a level of FPG of at least $126 \mathrm{mg} / \mathrm{dL}$ or a plasma glucose level of at least $200 \mathrm{mg} / \mathrm{dL}$ at 2 hours after a 75-g OGTT [13]. An FPG level of 100-125 mg/dL 
or a 2-hour glucose level of $140-199 \mathrm{mg} / \mathrm{dL}$ was referred to as impaired fasting glucose or impaired glucose tolerance, respectively. The diagnosis of prediabetes included either impaired fasting glucose or impaired glucose tolerance or both [13].

\section{Statistical analysis}

Statistical analysis was performed using IBM SPSS Statistics for Windows, Version 22.0 (IBM Corporation, Armonk, NY, USA). Categorical variables are described as numbers and percentages and were compared by the chi-square test or Fisher's exact test as appropriate. Continuous variables are reported as the median and interquartile range and were compared with the Mann-Whitney U test. The odds ratios (ORs) with 95\% confidence intervals (CIs) of T2DM and prediabetes of suboptimal glycemic control were analyzed by multivariate logistic regression and adjusted for potential confounders. The predictive performance of suboptimal glycemic control during pregnancy for postpartum
T2DM or prediabetes was determined by the receiver operating characteristic (ROC) curve. A value of $P<0.05$ was considered statistically significant.

\section{Ethical approval}

This study was approved by the Vajira Institution Review Board (certificate of approval no.138/2561) and was performed in compliance with the Declaration of Helsinki.

\section{Results}

\section{Characteristics of the study population}

A total of 706 women with GDM who had available data on plasma glucose levels during pregnancy and measurements of postpartum FPG and 75-g, 2-hour OGTT were included for analysis. Of these, 505 (71.5\%) women had optimal blood glucose control, and 201 (28.5\%) had suboptimal glucose control during pregnancy. The baseline characteristics of women with optimal and suboptimal glycemic control are presented in Table 1. Rates of multiparity, overweight or obese BMI $\left(\geq 25 \mathrm{~kg} / \mathrm{m}^{2}\right)$, history

Table 1 Characteristics of women with optimal and suboptimal glycemic control

\begin{tabular}{|c|c|c|c|}
\hline Characteristic & $\begin{array}{l}\text { Optimal glycemic control } \\
(n=505)\end{array}$ & $\begin{array}{l}\text { Suboptimal glycemic control } \\
(n=201)\end{array}$ & $P$ \\
\hline Age (years) & $32.0(28.0-36.0)$ & $33.0(28.0-37.0)$ & 0.514 \\
\hline$\geq 35$ years old & $190(37.6)$ & $82(40.8)$ & 0.434 \\
\hline Multiparity & $294(58.2)$ & $149(74.1)$ & $<0.001$ \\
\hline Prepregnancy BMI (kg/m²) & $22.6(20.4-25.7)$ & $26.3(23.0-30.7)$ & $<0.001$ \\
\hline Overweight or obese BMI ( $\geq 25$ kg/m²) & $146(28.9)$ & $119(59.2)$ & $<0.001$ \\
\hline History of T2DM in any first-degree relatives & $135(26.7)$ & $69(34.3)$ & 0.045 \\
\hline GCT value (mg/dL) & $164.0(152.0-182.0)$ & $177.0(156.5-210.0)$ & $<0.001$ \\
\hline \multicolumn{4}{|l|}{ 100-g OGTT (mg/dL) } \\
\hline Fasting value & $82.0(75.0-88.8)$ & $96.0(88.0-106.0)$ & $<0.001$ \\
\hline 1-hour value & $191.0(180.0-204.0)$ & $207.0(191.0-232.0)$ & $<0.001$ \\
\hline 2-hour value & $173.0(160.0-188.0)$ & $183.0(167.0-213.0)$ & $<0.001$ \\
\hline 3-hour value & $146.5(127.0-160.0)$ & $148.0(125.0-174.0)$ & 0.134 \\
\hline Gestational age at GDM diagnosis (weeks) & $29.0(17.0-31.0)$ & $18.5(10.0-29.0)$ & $<0.001$ \\
\hline Early-onset GDM (<24 weeks) & $156(30.9)$ & $121(60.2)$ & $<0.001$ \\
\hline Insulin use & $12(2.4)$ & $82(40.8)$ & $<0.001$ \\
\hline \multicolumn{4}{|l|}{ Type of insulin } \\
\hline Rapid-acting insulin & $1(0.2)$ & $10(5.0)$ & $<0.001$ \\
\hline Short-acting insulin & $0(0)$ & $22(10.9)$ & $<0.001$ \\
\hline Intermediate-acting insulin & $4(0.8)$ & $20(10.0)$ & $<0.001$ \\
\hline Premixed insulin & $8(1.6)$ & $51(25.4)$ & $<0.001$ \\
\hline Units of insulin used in pregnancy & $333(130-411)$ & $946(303-1758)$ & 0.006 \\
\hline \multicolumn{4}{|c|}{ Average plasma glucose during pregnancy (mg/dL) } \\
\hline Fasting value & $78.9(74.0-84.0)$ & $92.5(84.6-100.9)$ & $<0.001$ \\
\hline 2-hour postprandial value & $98.0(89.5-106.0)$ & $119.5(111.4-132.5)$ & $<0.001$ \\
\hline Neonatal birth weight (g) & $3220(2905-3549)$ & $3516(3039-3840)$ & $<0.001$ \\
\hline
\end{tabular}

Data are expressed as the median (IQR) or $\mathrm{n}(\%)$. 
of T2DM in any first-degree relatives, early-onset GDM $(<24$ weeks), and insulin use were significantly higher among women with suboptimal glycemic control than those with optimal glycemic control. The women with suboptimal glycemic control also had significantly higher median prepregnancy BMI, GCT, fasting, 1-hour and 2-hour OGTT values, units of insulin used, and neonatal birth weight but a significantly lower gestational age at GDM diagnosis.

\section{Rates of postpartum T2DM and prediabetes}

The rates of postpartum T2DM and prediabetes in women who had suboptimal blood glucose control during pregnancy were significantly higher than those in women with optimal blood glucose control: $22.4 \%$ vs. $3.0 \%$ for T2DM and $45.3 \%$ vs. $23.5 \%$ for prediabetes, $P<$ 0.001 for both (Table 2).

After adjustment for potential confounding factors (parity, prepregnancy BMI, history of $\mathrm{T} 2 \mathrm{DM}$ in any first-degree relatives, early-onset GDM, GCT and 100-g OGTT glucose values), suboptimal glucose control during pregnancy was an independent risk factor for developing either postpartum T2DM or prediabetes. The adjusted ORs were 8.4 (95\% CI, 3.5-20.3) for T2DM and 3.9 (95\% CI, 2.5-6.1) for prediabetes. Women with suboptimal control of either fasting or postprandial glucose during pregnancy had a lower OR for developing either T2DM or prediabetes than women with suboptimal control of both fasting and postprandial glucose levels: 3.7 (95\% CI, 2.1-6.5) vs. 5.3 (95\% CI, 3.1-9.1). Other independent risk factors for developing either postpartum T2DM or prediabetes were early-onset GDM and abnormal 100-g OGTT results, particularly abnormal fasting and 3-hour glucose values. The adjusted ORs were 1.5
(95\% CI, 1.1-2.2), 1.6 (95\% CI, 1.1-2.5) and 2.2 (95\% CI, $1.5-3.2)$, respectively.

\section{Comparison of different glucose thresholds for suboptimal glycemic control}

We also compared the predictive performances of postpartum T2DM or prediabetes of the three different glucose thresholds for suboptimal glycemic control: the thresholds being used in the present study (recommended by the ADA and ACOG), the threshold using any 2-hour postprandial glucose level of $150 \mathrm{mg} / \mathrm{dL}$ or higher [9] and the threshold using a mean daily glucose of more than $95 \mathrm{mg} / \mathrm{dL}$ [10]. The glucose thresholds recommended by the ADA and ACOG yielded the best predictive performance with an area under the ROC curve of 0.677 ( $95 \%$ CI $0.635-0.720$ ), followed by the threshold using a mean daily glucose of more than $95 \mathrm{mg} / \mathrm{dL}$ [10] and the threshold using any 2-hour postprandial glucose level of $150 \mathrm{mg} / \mathrm{dL}$ or higher [9] (Fig. 1). The sensitivities, specificities, positive predictive values, negative predictive values, and area under the ROC curves of the three predictive criteria are presented in Table 3.

\section{Discussion}

The findings of this study indicated that blood glucose levels throughout pregnancy of women with GDM were directly related to the risk of developing T2DM or prediabetes at 6 weeks postpartum. This association was independent of the glucose levels measured at the time of GDM diagnosis, as assessed by the 100-g OGTT values. Our observation suggests that not merely the presence of GDM, which is a well-known risk factor for T2DM [15], but also glycemic control plays an important role in modifying the risk of postpartum T2DM as well as prediabetes. Pregnant women with GDM should be educated

Table 2 Risks of postpartum type 2 diabetes mellitus or prediabetes in women with optimal and suboptimal glycemic control

\begin{tabular}{|c|c|c|c|c|c|c|}
\hline \multirow[t]{3}{*}{ Glucose control } & \multicolumn{6}{|c|}{ Postpartum risk } \\
\hline & \multicolumn{2}{|c|}{$\begin{array}{l}\text { Either T2DM or prediabetes } \\
(n=270)\end{array}$} & \multicolumn{2}{|c|}{ T2DM $(n=60)$} & \multicolumn{2}{|c|}{ Prediabetes $(n=210)$} \\
\hline & $n(\%)$ & $\begin{array}{l}\text { Adjusted OR } \\
(95 \% \mathrm{Cl})\end{array}$ & $n(\%)$ & $\begin{array}{l}\text { Adjusted OR } \\
(95 \% \mathrm{Cl})\end{array}$ & $n(\%)$ & $\begin{array}{l}\text { Adjusted OR } \\
(95 \% \mathrm{Cl})\end{array}$ \\
\hline Optimal glycemic control $(n=505)$ & $134 / 505(26.5)$ & 1.0 (reference) & $15 / 505(3.0)$ & 1.0 (reference) & $119 / 505(23.5)$ & 1.0 (reference) \\
\hline Suboptimal glycemic control $(n=201)$ & $136 / 201(67.7)$ & $4.4(2.9-6.8)$ & $45 / 201(22.4)$ & $8.4(3.5-20.3)$ & $91 / 201(45.3)$ & $3.9(2.5-6.1)$ \\
\hline \multicolumn{7}{|l|}{ Pattern of suboptimal glycemic control } \\
\hline Either fasting or postprandial glucose $(n=66)$ & $39 / 66(59.1)$ & $3.7(2.1-6.5)$ & $4 / 66(6.1)$ & $2.6(0.5-13.6)$ & $35 / 66(53.0)$ & $3.9(2.2-7.0)$ \\
\hline Both fasting and postprandial glucose $(n=135)$ & $97 / 135(71.9)$ & $5.3(3.1-9.1)$ & $41 / 135(30.4)$ & $15.0(5.4-41.7)$ & $56 / 135(41.5)$ & $4.0(2.3-7.1)$ \\
\hline
\end{tabular}

BMI Body mass index; CI Confidence interval; GCT Glucose challenge test; GDM Gestational diabetes mellitus; OGTT Oral glucose tolerance test; OR Odds ratio; T2DM Type 2 diabetes mellitus

${ }^{\text {a }}$ Adjusted for parity, prepregnancy BMI, history of T2DM in any first-degree relatives, early-onset GDM, GCT and 100-g OGTT glucose values. 


\section{ROC Curve}

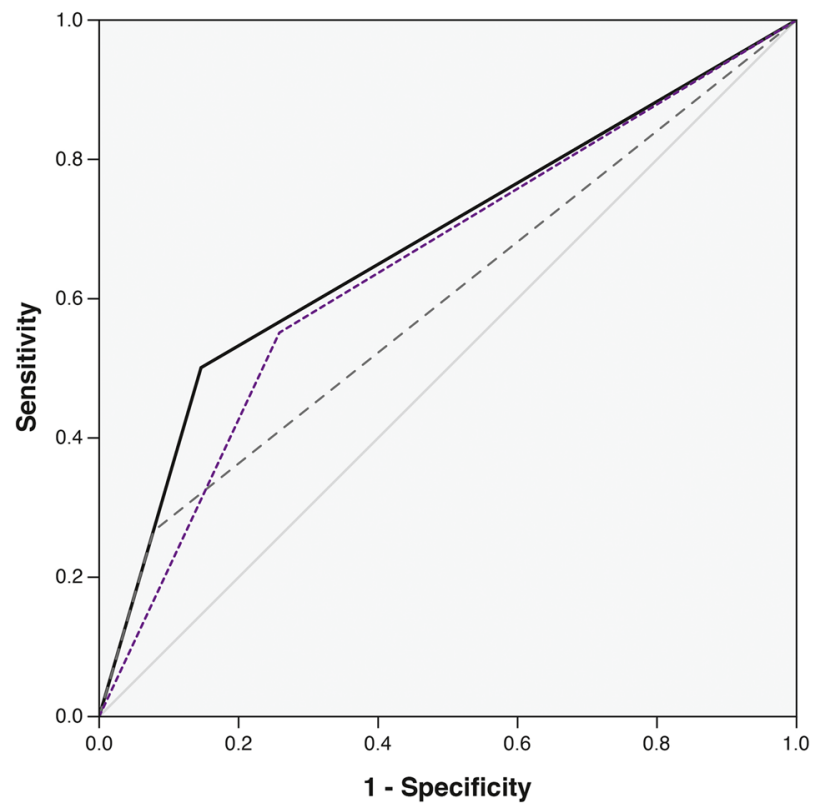

- The present study

---- Mean daily glucose $>95 \mathrm{mg} / \mathrm{dL}$

- - Any 2-h postprandial glocose

$>/=150 \mathrm{mg} / \mathrm{dL}$

Reference Line

Fig. 1 Receiver operating characteristic curves of the three criteria used to define suboptimal glycemic control for the prediction of postpartum type 2 diabetes mellitus or prediabetes

Table 3 Predictive performance for postpartum type 2 diabetes mellitus or prediabetes according to the three criteria for defining suboptimal glycemic control

\begin{tabular}{|c|c|c|c|c|c|}
\hline Criteria & $\begin{array}{l}\text { Sensitivity (\%) } \\
(95 \% \mathrm{Cl})\end{array}$ & $\begin{array}{l}\text { Specificity (\%) } \\
(95 \% \mathrm{Cl})\end{array}$ & $\begin{array}{l}\text { PPV (\%) } \\
(95 \% \mathrm{Cl})\end{array}$ & $\begin{array}{l}\text { NPV (\%) } \\
(95 \% \mathrm{Cl})\end{array}$ & $\begin{array}{l}\text { AUC } \\
(95 \% \mathrm{Cl})\end{array}$ \\
\hline The present study ${ }^{a}$ & $50.4(44.3-56.5)$ & $85.1(81.4-88.3)$ & $67.7(61.9-73.0)$ & $73.5(68.3-75.1)$ & $0.677(0.635-0.720)$ \\
\hline $\begin{array}{l}\text { Any 2-hour postprandial glucose } \geq \\
150 \mathrm{mg} / \mathrm{dL}\end{array}$ & $26.7(21.5-32.4)$ & $92.2(89.3-94.5)$ & $67.9(59.2-75.6)$ & $67.0(65.3-68.7)$ & $0.594(0.550-0.639)$ \\
\hline Mean daily glucose $>95 \mathrm{mg} / \mathrm{dL}$ & $55.2(49.0-61.2)$ & $74.1(69.7-78.1)$ & $56.9(52.1-61.5)$ & $72.8(69.8-75.5)$ & $0.646(0.604-0.689)$ \\
\hline
\end{tabular}

AUC Area under the receiver operating characteristic curve; Cl Confidence interval; NPV Negative predictive value; PPV Positive predictive value

${ }^{a}$ The criteria for defining suboptimal glycemic control used in the present study were $\geq 2$ occasions of fasting glucose $\geq 95 \mathrm{mg} / \mathrm{dL}$ and/or 2 -hour postprandial glucose $\geq 120 \mathrm{mg} / \mathrm{dL}$.

about the benefits and targets of optimal glycemic control to decrease both intra- and postpartum adverse effects. Regular monitoring of plasma glucose levels and timely initiation of insulin therapy should be considered to maintain adequate glycemic control throughout pregnancy.

Furthermore, we found a direct association between the degree of suboptimal glycemic control, as characterized by the pattern of elevated fasting and postprandial glucose levels, and the development of T2DM or prediabetes postpartum. Risks of postpartum T2DM or prediabetes were increased by 3.7 -fold among women with suboptimal control of either fasting or postprandial glucose and 5.3-fold among women with suboptimal control of both fasting and postprandial glucose compared to women with optimal glycemic control.

Two hypotheses have been proposed to explain the association between suboptimal glycemic control during GDM pregnancy and the development of postpartum T2DM or prediabetes. First, this may be related to the severity of chronic $\beta$-cell dysfunction and insulin resistance that manifests as hyperglycemia in pregnancy $[11,16,17]$ and translates into a continuum of dysglycemia (prediabetes and T2DM) in the postpartum period or later in life $[16,17]$. Saisho et al. [11], who used the disposition index to evaluate $\beta$-cell dysfunction, found 
an association of the level of $\beta$-cell dysfunction with the severity of glucose intolerance (assessed by the fasting and mean daily blood glucose levels) during pregnancy among Japanese women with GDM. Other authors also observed a correlation between the degree of glucose intolerance in pregnancy and the magnitudes of $\beta$-cell dysfunction and insulin resistance in Western pregnant women [16, 17]. Given that insulin secretory defects and insulin resistance are well recognized as precursors of T2DM and prediabetes [5, 6], the risk of developing either type of glucose intolerance postpartum was therefore higher in women with a more severe degree of suboptimal glycemic control during pregnancy than in those with a lesser extent of suboptimal glycemic control.

The second hypothesis is that chronic exposure of pancreatic islets to elevated glucose levels during pregnancy exerts toxicity on $\beta$-cells by oxidative stress, leading to more $\beta$-cell dysfunction and cell death and consequent prediabetes or T2DM after pregnancy $[18,19]$. These cascade events were demonstrated in several studies that found a reduction in $\beta$-cell volume among patients with T2DM compared to nondiabetic subjects [20-23]. Nevertheless, such prior studies were limited by being a cross-sectional research design and not being conducted in vivo. Further longitudinal studies are therefore needed to compare the changes in $\beta$-cell mass over time from antepartum to postpartum among women with GDM who develop and do not develop postpartum T2DM or prediabetes.

Given that there have been no recommendations from the expert panels regarding plasma glucose thresholds during pregnancy that are related to a reduced risk of postpartum T2DM or prediabetes, we then adopted the fasting and postprandial glucose targets, as recommended by the ADA and ACOG to reduce the risk of macrosomia [12, 13], to classify the plasma glucose levels of women in this study as indicating optimal or suboptimal glycemic control. Previous studies have reported that intermittent high glucose levels rather than persistent hyperglycemia stimulate reactive oxygen species overproduction, $\beta$-cell apoptosis and dysfunction [24-26]. Hence, we focused on high blood glucose levels at different time points in preference over high mean blood glucose levels. In our study, optimal glycemic control was defined as no more than one occasion of elevated FPG or 2-hour postprandial glucose. Several studies used less than three occasions of elevated glucose values and some clinics use less than $50 \%$ of elevated values out of all determined values to define optimal control $[9,27]$. We selected this strict criterion aiming to alert the woman and her obstetrician to be cautious about the condition, so diet or behavioral modifications would be more focused.
With a fasting glucose level of $95 \mathrm{mg} / \mathrm{dL}$ or higher and/ or 2-hour postprandial glucose of $120 \mathrm{mg} / \mathrm{dL}$ or higher on at least two occasions, the predictive performance of these glucose thresholds for postpartum T2DM or prediabetes yielded moderate discriminatory power (an area under the ROC curve of 0.677). Aside from these glucose thresholds, two other studies that used different glucose thresholds to define suboptimal glycemic control during pregnancy also reported an increased risk of postpartum glucose intolerance or future T2DM among women with suboptimal glycemic control $[9,10]$. When a comparison among the three glucose thresholds was made, we found that the thresholds used in our study yielded the best predictive performance for T2DM or prediabetes at 6 weeks postpartum. Our findings suggested that the fasting and 2-hour postprandial glucose targets recommended by the ADA and ACOG to reduce the risk of macrosomia could also lessen the risk of developing postpartum T2DM or prediabetes.

Aside from T2DM, we also paid attention to the development of prediabetes because this metabolic state represents an intermediate hyperglycemic state for progression to T2DM [28]. As the lifetime risk of progressing from prediabetes to T2DM has been reported to be high at $74 \%$ [29], a reduced risk of postpartum prediabetes should be as important as that of T2DM. This study found that both spectra of glucose intolerance were significantly decreased with optimal glycemic control.

Notably, the present study focused specifically on the development of dysglycemia at 6 weeks postpartum, which is the usual time for a postpartum checkup. Screening for T2DM or prediabetes after delivery was performed in the same setting for convenience and early detection of any dysglycemic condition. Although data on the long-term impact of glycemic control during pregnancy on glucose intolerance are interesting, we were aware of other factors that may influence the risk of subsequent T2DM or prediabetes, such as diet and physical activity. A well-designed prospective study controlling all relevant factors with a long-term follow-up may be able to provide a definite answer regarding an association of glycemic control during pregnancy and the long-term risk of dysglycemia.

The strength of our study included having a large number of pregnant women with multiple fasting and postprandial blood glucose measurements throughout pregnancy. In addition, all blood glucose specimens collected in our institution were measured using the same automated glucose analyzer, which was calibrated regularly to obtain accurate results. Furthermore, the diagnoses of GDM and postpartum T2DM or prediabetes were made according to the standard guidelines. Nevertheless, there are a few limitations that one should 
bear in mind when applying our results in clinical practice. Although frequent blood glucose monitoring is an integral part of achieving glycemic targets, only blood glucose levels during antenatal visits were used in this study. This was because most women in our study had limited ability or resources to do frequent self-monitoring of their blood glucose levels. In this situation, a regular blood glucose measurement during antenatal care may be needed to define optimal or suboptimal glycemic control. Second, our study was limited by the use of Carpenter and Coustan criteria to diagnose GDM. We cannot confirm the validity of our findings in settings that use different approaches to GDM screening and diagnosis. Lastly, some may question the possibility of unrecognized pregestational diabetes among these women. It was less likely in our study because all of the study population had an FPG less than $126 \mathrm{mg} /$ $\mathrm{dL}$ (before ingestion of the 100-g glucose load) and no one (among a few who had available hemoglobin A1c test) had an A1c of $6.5 \%$ or higher [30, 31].

\section{Conclusion}

Our study demonstrated that glucose levels during GDM pregnancy have an impact on the risk of developing T2DM or prediabetes at 6 weeks postpartum. Optimal glycemic control throughout pregnancy is therefore necessary to reduce these risks. Aside from weight loss and insulin therapy that can temporarily improve $\beta$-cell function, future research is needed to search for interventions that can permanently arrest the progression of $\beta$-cell dysfunction in women with GDM.

\section{Abbreviations \\ ACOG: American College of Obstetricians and Gynecologists; ADA: American Diabetes Association; BMI: Body mass index; Cl: Confidence interval; FPG: Fast- ing plasma glucose; GCT: Glucose challenge test; GDM: Gestational diabetes mellitus; OGTT: Oral glucose tolerance test; OR: Odds ratio; ROC: Receiver operating characteristic; T2DM: Type 2 diabetes mellitus.}

\section{Acknowledgements}

Not Applicable.

\section{Authors' contributions}

CP: study design, data collection and interpretation, manuscript writing, proof and validation; and ST: manuscript writing, proof and validation. All authors have critically revised the manuscript and approved the final version.

\section{Funding}

This work was supported by the Navamindradhiraj University Research Fund. The funder had no role in the design of the study; collection, analysis, and interpretation of data; preparation or approval of the manuscript; and decision to submit the manuscript for publication.

\section{Availability of data and materials}

The datasets used and analyzed in this study are available from the corresponding author on reasonable request.

\section{Declarations}

\section{Ethics approval and consent to participate}

The study protocol was approved by the Vajira Institutional Review Board (approval no.138/2561). The data analysis procedures are in line with the guidelines in the Declaration of Helsinki. Informed consent was waived by the Ethics Committee of the Faculty of Medicine Vajira Hospital, Navamindradhiraj University. Permission to access and use the data was granted by the dean of the Faculty of Medicine Vajira Hospital.

\section{Consent for publication}

Not applicable.

\section{Competing interests}

The authors declare that they have no competing interests.

Received: 3 October 2020 Accepted: 18 December 2021

Published online: 08 January 2022

\section{References}

1. Zhu Y, Zhang C. Prevalence of gestational diabetes and risk of progression to type 2 diabetes: a global perspective. Curr Diab Rep. 2016;16:7.

2. Plows JF, Stanley JL, Baker PN, Reynolds CM, Vickers MH. The pathophysiology of gestational diabetes mellitus. Int J Mol Sci. 2018;19:3342.

3. Muche AA, Olayemi OO, Gete YK. Effects of gestational diabetes mellitus on risk of adverse maternal outcomes: a prospective cohort study in Northwest Ethiopia. BMC Pregnancy Childbirth. 2020;20(1):73.

4. Phaloprakarn C, Tangjitgamol S. Risk score for predicting primary cesarean delivery in women with gestational diabetes mellitus. BMC Pregnancy Childbirth. 2020;20(1):607.

5. Lorenzo C, Wagenknecht LE, D'Agostino RB Jr, Rewers MJ, Karter AJ, Haffner SM. Insulin resistance, $\beta$-cell dysfunction, and conversion to type 2 diabetes in a multiethnic population: The insulin resistance atherosclerosis study. Diabetes Care. 2010;33:67-72.

6. Tura A, Göbl C, Moro E, Pacini G. Insulin resistance and beta-cell dysfunction in people with prediabetes according to criteria based on glycemia and glycosylated hemoglobin. Endocr J. 2017;64:117-22.

7. González-Quintero VH, Istwan NB, Rhea DJ, Rodriguez LI, Cotter A, Carter $J$, et al. The impact of glycemic control on neonatal outcome in singleton pregnancies complicated by gestational diabetes. Diabetes Care. 2007;30:467-70.

8. Langer O, Rodriguez DA, Xenakis EM, McFarland MB, Berkus MD, Arrendondo F. Intensified versus conventional management of gestational diabetes. Am J Obstet Gynecol. 1994;170:1036-46.

9. Greenberg LR, Moore TR, Murphy H. Gestational diabetes mellitus: antenatal variables as predictors of postpartum glucose intolerance. Obstet Gynecol. 1995;86:97-101.

10. Yefet E, Schwartz N, Sliman B, Ishay A, Nachum Z. Good glycemic control of gestational diabetes mellitus is associated with the attenuation of future maternal cardiovascular risk: a retrospective cohort study. Cardiovasc Diabetol. 2019;18:75.

11. Saisho Y, Miyakoshi K, Tanaka M, Shimada A, Ikenoue S, Kadohira I, et al. Beta cell dysfunction and its clinical significance in gestational diabetes. Endocr J. 2010;57:973-80.

12. American Diabetes Association. 14. Management of diabetes in pregnancy: standards of medical care in diabetes-2020. Diabetes Care. 2020;43(Suppl 1):S183-S92.

13. Committee on Practice Bulletins-Obstetrics. ACOG Practice Bulletin No. 190: Gestational diabetes mellitus. Obstet Gynecol. 2018;131:e49-e64.

14. Carpenter MW, Coustan DR. Criteria for screening tests for gestational diabetes. Am J Obstet Gynecol. 1982;144:768-73.

15. Bellamy L, Casas JP, Hingorani AD, Williams D. Type 2 diabetes mellitus after gestational diabetes: a systematic review and meta-analysis. Lancet. 2009;373:1773-9.

16. Kramer CK, Swaminathan B, Hanley AJ, Connelly PW, Sermer M, Zinman $B$, et al. Each degree of glucose intolerance in pregnancy predicts distinct trajectories of $\beta$-cell function, insulin sensitivity, and glycemia in the first 3 years postpartum. Diabetes Care. 2014;37:3262-9. 
17. Retnakaran R, Qi Y, Sermer M, Connelly PW, Hanley AJ, Zinman B. Glucose intolerance in pregnancy and future risk of pre-diabetes or diabetes. Diabetes Care. 2008;31:2026-31.

18. Cerf ME. Beta cell dysfunction and insulin resistance. Front Endocrinol (Lausanne). 2013:4:37.

19. Saisho Y. $\beta$-cell dysfunction: its critical role in prevention and management of type 2 diabetes. World J Diabetes. 2015;6:109-24.

20. Yoon KH, Ko SH, Cho JH, Lee JM, Ahn YB, Song KH, et al. Selective betacell loss and alpha-cell expansion in patients with type 2 diabetes mellitus in Korea. J Clin Endocrinol Metab. 2003;88:2300-8.

21. Sakuraba H, Mizukami H, Yagihashi N, Wada R, Hanyu C, Yagihashi S. Reduced beta-cell mass and expression of oxidative stress-related DNA damage in the islet of Japanese Type II diabetic patients. Diabetologia. 2002:45:85-96.

22. Rahier J, Guiot Y, Goebbels RM, Sempoux C, Henquin JC. Pancreatic beta-cell mass in European subjects with type 2 diabetes. Diabetes Obes Metab. 2008;10(Suppl 4):32-42.

23. Butler AE, Janson J, Bonner-Weir S, Ritzel R, Rizza RA, Butler PC. Beta-cell deficit and increased beta-cell apoptosis in humans with type 2 diabetes. Diabetes. 2003;52:102-10.

24. Quagliaro L, Piconi L, Assaloni R, Martinelli L, Motz E, Ceriello A. Intermittent high glucose enhances apoptosis related to oxidative stress in human umbilical vein endothelial cells: the role of protein kinase $C$ and NAD(P)H-oxidase activation. Diabetes. 2003;52:2795-804.

25. Piconi L, Quagliaro L, Assaloni R, Da Ros R, Maier A, Zuodar G, et al. Constant and intermittent high glucose enhances endothelial cell apoptosis through mitochondrial superoxide overproduction. Diabetes Metab Res Rev. 2006;22:198-203.

26. Shao C, Gu J, Meng X, Zheng H, Wang D. Systematic investigation into the role of intermittent high glucose in pancreatic beta-cells. Int J Clin Exp Med. 2015:8:5462-9.

27. Pallardo LF, Herranz L, Martin-Vaquero P, Garcia-Ingelmo T, Grande C, Jañez M. Impaired fasting glucose and impaired glucose tolerance in women with prior gestational diabetes are associated with a different cardiovascular profile. Diabetes Care. 2003;26(8):2318-22.

28. Hostalek U. Global epidemiology of prediabetes - present and future perspectives. Clin Diabetes Endocrinol. 2019;5:5.

29. Ligthart S, van Herpt TT, Leening MJ, Kavousi M, Hofman A, Stricker BH, et al. Lifetime risk of developing impaired glucose metabolism and eventual progression from prediabetes to type 2 diabetes: a prospective cohort study. Lancet Diabetes Endocrinol. 2016;4:44-51.

30. International Association of Diabetes and Pregnancy Study Groups Consensus Panel, Metzger BE, Gabbe SG, Persson B, Buchanan TA, Catalano PA, et al. International association of diabetes and pregnancy study groups recommendations on the diagnosis and classification of hyperglycemia in pregnancy. Diabetes Care. 2010;33(3):676-82.

31. Granada C, Forbes J, Sangi-Haghpeykar H, Davidson C. Can overt diabetes mellitus be predicted by an early $\mathrm{A} 1 \mathrm{C}$ value in gestational diabetics? $\mathrm{J}$ Reprod Med. 2014;59(7-8):343-7.

\section{Publisher's Note}

Springer Nature remains neutral with regard to jurisdictional claims in published maps and institutional affiliations.

Ready to submit your research? Choose BMC and benefit from:

- fast, convenient online submission

- thorough peer review by experienced researchers in your field

- rapid publication on acceptance

- support for research data, including large and complex data types

- gold Open Access which fosters wider collaboration and increased citations

- maximum visibility for your research: over $100 \mathrm{M}$ website views per year

At BMC, research is always in progress.

Learn more biomedcentral.com/submissions 